\title{
Parametric analysis of Li-ion battery based on laboratory tests
}

\author{
Artur Kopczyński ${ }^{1, *}$, Zhiyin Liu ${ }^{1}$, and Pawet Krawczyk ${ }^{1}$ \\ ${ }^{1}$ Warsaw University of Technology, Department of Multisource Propulsion Systems, Narbutta 84, \\ 02-524 Warsaw, Poland
}

\begin{abstract}
The study of Li-ion battery based on laboratory tests was presented and analysed taking into consideration various aspects. The tests with different charging and discharging currents were carried out. Moreover, some additional tests with the use of temperature chamber were applied. The results derived from laboratory tests allowed to obtain the characteristics of the electromotive force of two types of Li-ion cylindrical cell batteries. Subsequently, the influence of temperature on battery useful capacity was analysed. Therefore, the characteristics of internal resistance for studied batteries were determined based on obtained results and according to battery non-linear modelling $[1,2]$. Finally, the possibilities for further development of the presented research have been considered.
\end{abstract}

\section{Introduction}

Electrochemical batteries are present in many branches of industry and science, and they are increasingly used. Nevertheless, electric vehicles are still one of the main developing sectors that benefit from them [2]. Among the electrochemical batteries available on the market, Li-ion batteries are characterised by properties that make them currently the most popular choice for electric and hybrid vehicles [2, 4]. The electrochemical battery parameters depending on the operating conditions are one of the most important factors affecting the functionality of electric vehicles. Taking into account the fact that hybrid and electric vehicles are becoming more and more popular, one should keep in mind that they must properly operate in very diverse climate throughout the world. This means that such a vehicle can be used in an atmosphere in which temperatures reach over $30^{\circ} \mathrm{C}$ during the summer and $-10^{\circ} \mathrm{C}$ or even $-30^{\circ} \mathrm{C}$ in winter. In such extreme conditions, the electrochemical battery parameters are definitely different. Currently, the driving range of electric vehicles is insufficient to fully replace conventional vehicles [5]. That is why it is necessary to look for new solutions to increase the energetic effectiveness of electric drive systems [6], and hence appropriate mathematical models of individual components [7]. Such models are nowadays ambiguously verified. The development of electrochemical accumulator technologies, both in the context of energy density, the shape of a cell, and electrolyte type, requires the definition of guidelines for their comparison. Determination of parameters such as electromotive force and internal resistance depending on the Stage of Charge (SOC) $[8,9]$ or

\footnotetext{
* Corresponding author: artur.kopczynski@simr.pw.edu.pl
} 
internal temperature of a particular type of battery is necessary for the appropriate modelling of the behaviour of the battery in the analysed system. The studied in this paper approach to Li-ion battery modelling was developed by Antoni Szumanowski and Yuhua Chang [1].

\section{Laboratory stand}

Laboratory tests were carried out at the stand, the scheme of which is presented in Figure 1. It consists of tested batteries (described in chapter 3), AIM-TTI LD300 electric power supply (charger), VOLTCRAFT HPS 11560 electric load (discharger), National Instruments USB6008 measuring multifunction card and Tektronix current sensor.

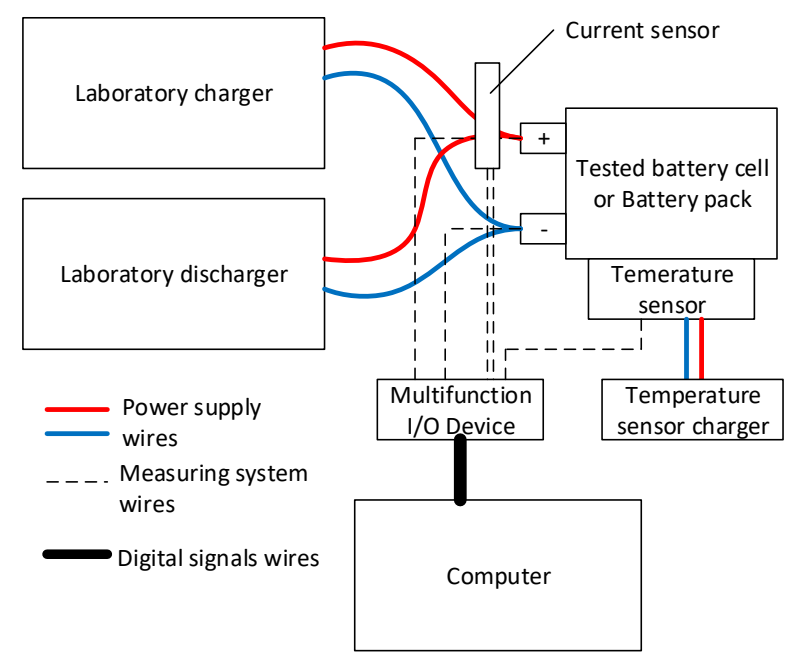

Fig. 1. Scheme of the measurement system for laboratory tests.

The terminals of the tested battery have been connected simultaneously to the charger and the discharger by means of wires. A current sensor was installed on the wires connected to the positive terminal. The temperature sensor was attached to the battery surface. The battery terminals were also directly connected to the multifunction card, which recorded the battery voltage. Wires transferring signals from the current sensor (in the form of voltage, which was then scaled to current values) and from the temperature sensor were also connected to the multifunction card. In addition, in some studies, a temperature chamber (Votsch) was used to keep a constant ambient temperature. In this case, the tested battery, together with the temperature sensor, was located in the temperature chamber, while the other components were outside. The tests were carried out in such a way that there was no simultaneous charging and discharging of the battery. It means that during one test the battery was either only charged or only discharged.

\section{Battery}

The choice of the type of electrochemical cells is not always obvious. Usually, their shape and size, as well as operating parameters, are taken into account. Most electric and hybrid vehicles use Li-Ion batteries. However, when it comes to the shape of a cell, there is definitely more variation. For example, small cylindrical cells are typically used in Tesla vehicles [10] and prismatic cells in the Nissan Leaf [11]. The cylindrical cells, with 18650 type of housing, were decided to be the subject of the presented research because of their widespread use, not only in the electric vehicle sector, and their high availability on the market. In battery packets 
made of this type of cells, it is easier to implement the Battery Management System (BMS) due to the smaller current loads of a single cell. In addition, small cylindrical cells are more reproducible. Their disadvantage is the need to make a large number of connections inside the package, which in turn creates a risk of failure and increase the internal resistance of the packet. Cells from two different manufacturers were selected for the research. The Panasonic cell is used in many applications and the Samsung one which has very good current load parameters. The parameters of the two cells are presented in Table 1.

Table 1. Parameters of tested battery $[12,13]$.

\begin{tabular}{|c|c|}
\hline & 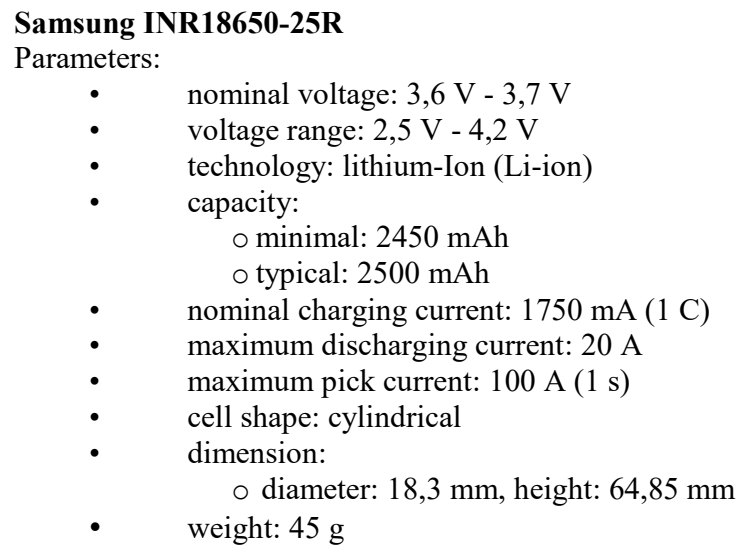 \\
\hline \% & $\begin{array}{cl}\text { Panasonic NCR18650B } \\
\text { Parameters: } \\
\text { - } & \text { nominal voltage: } 3,7 \mathrm{~V} \\
\text { - } & \text { voltage range: } 2,5 \mathrm{~V}-4,2 \mathrm{~V} \\
\text { - } & \text { technology: lithium-Ion (Li-ion) } \\
& \text { capacity: } \\
& \text { o minimal: } 3250 \mathrm{mAh} \\
& \text { o typical: } 3350 \mathrm{mAh} \\
\text { - } & \text { maximal charging current: } 1625 \mathrm{~mA}(0,5 \mathrm{C}) \\
\text { - } & \text { maximum discharging current: } 4,87 \mathrm{~A} \\
\text { - } & \text { cell shume: cylindrical } \\
\text { - } & \text { dimension: } \\
& \text { o diameter: } 18,5 \mathrm{~mm} \text {, height: } 65,3 \mathrm{~mm} \\
\text { - } & \text { weight: } 47,5 \mathrm{~g}\end{array}$ \\
\hline
\end{tabular}

\section{Laboratory test results}

The test results are carried out by the laboratory test described in section 3. Two Li-ion batteries are tested, made from Samsung INR18650-25R cells and Panasonic NCR-18650B cells. The tests are carried out for both batteries respectively, and after each discharge, the batteries are charged with a nominal charging current at room temperature $\left(20^{\circ} \mathrm{C}\right)$, regardless of the discharge conditions.

The first group of tests assumed the discharge of cells at room temperature for different values of currents. The current values are selected based on the nominal capacity of the battery, i.e. $1 \mathrm{C}, 1.5 \mathrm{C}, 2 \mathrm{C}, 3 \mathrm{C}$ for the Panasonic cells and $1 \mathrm{C}, 1.5 \mathrm{C}, 2 \mathrm{C}, 3 \mathrm{C}, 4 \mathrm{C}$ for the Samsung cells.

In the second group of tests, the climatic chamber is used and tests are carried out for both batteries with discharging current $1 \mathrm{C}$ at $20^{\circ} \mathrm{C}, 0^{\circ} \mathrm{C}$ and $-30^{\circ} \mathrm{C}$. 


\subsection{Laboratory test results with different discharging current}

For measurements at room temperature for Panasonic NCR-18650B battery, the results of individual measurements are shown in Figure 2.

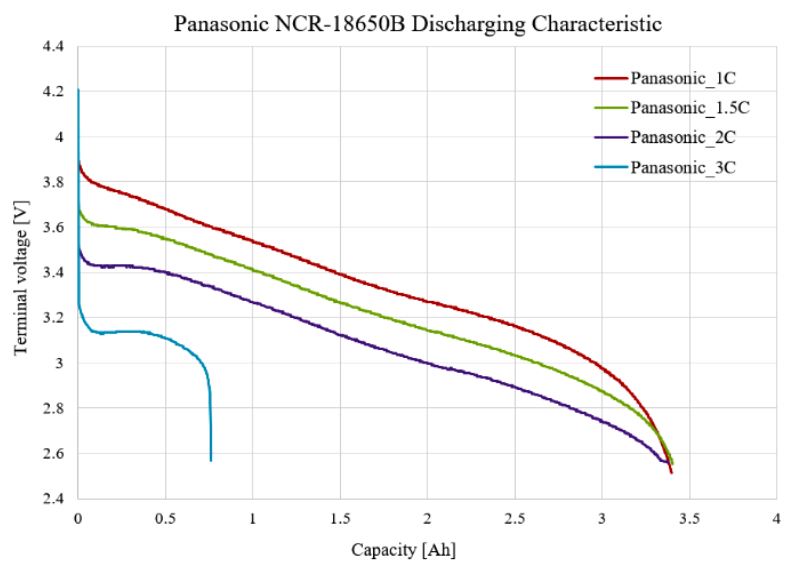

Fig. 2. Discharging characteristic of Panasonic NCR-18650B battery with different discharging current at room temperature $\left(20^{\circ} \mathrm{C}\right)$.

According to the test result with $3 \mathrm{C}$ discharging current, the battery is not capable to handle such current. The available battery capacity at this load is only $20 \%$ of the nominal capacity. It is a consistent result with predictions made based on the manufacturer's data. In addition, according to the manufacturer's data, the maximum continuous discharging current is $4.85 \mathrm{~A}$, which means that recommended continuous discharging current is not higher than $1.5 \mathrm{C}$. The test results also present that the terminal voltage of the battery drops rapidly when the discharged capacity is over $90 \%$, which means the internal resistance increases significantly. In modern electric and hybrid vehicles, the battery state of charge is limited to avoid the deep discharging. By reserving $20-30 \%$ of the battery capacity, it could increase the life cycle of battery and efficiency.

For measurements at room temperature for Samsung INR18650-25R battery, the results of individual measurements are shown in Figure 3.

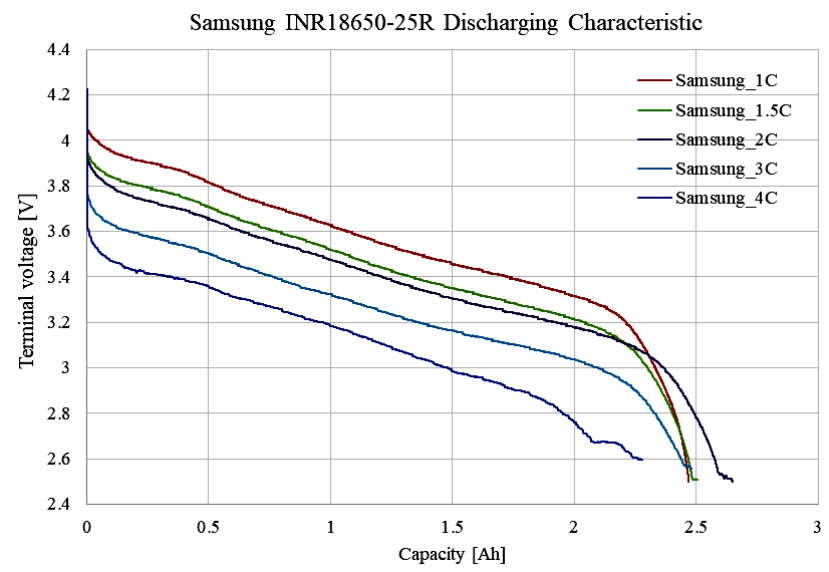

Fig. 3. Discharging characteristic of Samsung INR18650-25R battery with different discharging currents at room temperature $\left(20^{\circ} \mathrm{C}\right)$. 
The test results for Samsung INR18650-25R battery are similar to those of Panasonic battery. However, it shows a better performance for high current discharging up to $4 \mathrm{C}$.

\subsection{Laboratory test results with different temperatures}

Subsequently, laboratory tests of both battery discharging with different temperatures are carried out in the climatic chamber. The test results are presented in Figure 4 and 5. For each test, the batteries are placed in the climatic chamber for enough time until the battery housings keep the same temperature as pre-set. After the discharging, the batteries are kept at room temperature for enough time before charging.

The tests in the climatic chamber clearly present the effect of temperature on the available capacity of the batteries. For the measurements at $20^{\circ} \mathrm{C}$ and $0^{\circ} \mathrm{C}$, the difference is no more than $7 \%$ for Panasonic and $1.5 \%$ for Samsung. In both cases, the battery terminal voltage is higher at $20^{\circ} \mathrm{C}$ than that at $0^{\circ} \mathrm{C}$ during the discharging. An interesting situation is observed for the temperature of $-30^{\circ} \mathrm{C}$. In the case of Panasonic battery after applying the load, the potential dropped below $2.5 \mathrm{~V}$ within a few seconds and the apparatus automatically disconnected the load. However, the Samsung battery has retained slightly worse parameters than in the case of measurement at $0^{\circ} \mathrm{C}$, which should be considered a very good result that testifies to the high quality of the tested cells. From the voltage waveform in this test, a slight voltage jump is puzzling around the middle of the discharge cycle. It can be caused by the heating of the cell during operation which means that the temperature inside the battery has increased. Nevertheless, it seems that the nature of temperature rise under the influence of chemical changes in its interior would be calmer. In this case, too, it seems appropriate to repeat this study.

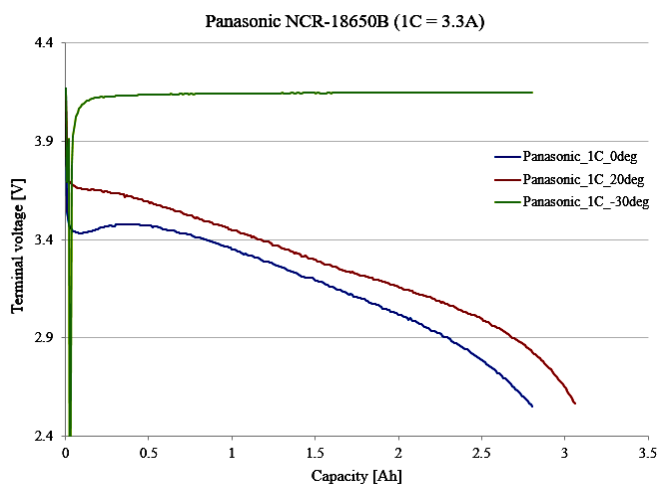

Fig. 4. Discharging characteristic of Panasonic NCR-18650B with $1 \mathrm{C}$ discharging rate at different temperatures.

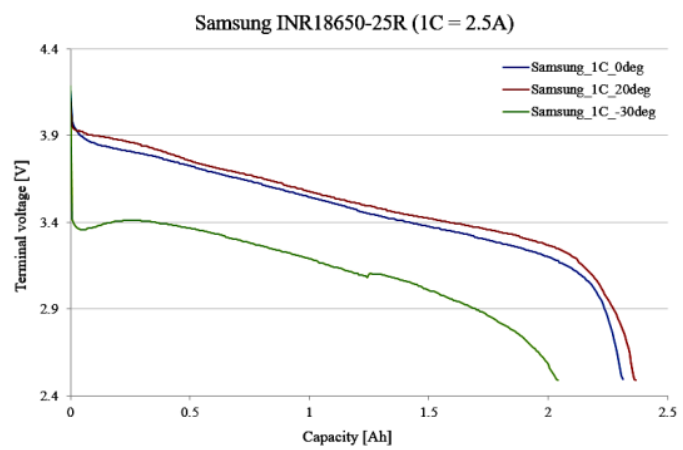

Fig. 5. Discharging characteristic of Samsung INR18650-25R with 1C discharging rate at different temperatures. 


\section{Determination of battery parameters}

According to the basic battery model, the equation regarding battery electromotive force (EMF), terminal voltage, current and internal resistance is as below. The sign of current value depends on the direction of the current, which indicates charging and discharging respectively. EMF and internal resistance of battery are functions of battery state of charge value $k$.

$$
E(k)=U \pm I R(k)
$$

The terminal voltage $(U)$ and discharging current $(I)$ of the battery are measured in the laboratory test. For each discharging current, we received a characteristic of terminal voltage. With at least two characteristics, we can calculate EMF value $E$. With these test results, it is possible to define the function of battery terminal voltage $U(k)$. Based on test results, the high order polynomial equations are used to fit the characteristic (see Figure 6).

$$
\left\{\begin{array}{l}
E(k)=U_{1}(k)+I_{1} R(k) \\
E(k)=U_{2}(k)+I_{2} R(k)
\end{array}\right.
$$

Then,

$$
\left\{\begin{array}{l}
E(k)=\frac{I_{1}}{I_{1}-I_{2}} U_{2}(k)-\frac{I_{2}}{I_{1}-I_{2}} U_{1}(k) \\
R(k)=\frac{U_{2}(k)-U_{1}(k)}{I_{1}-I_{2}}
\end{array}\right.
$$
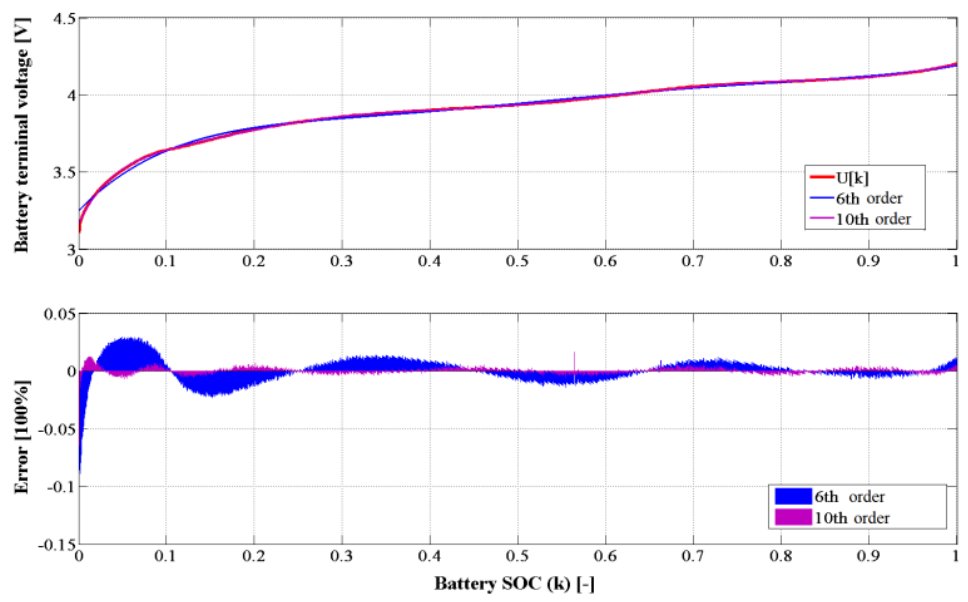

Fig. 6. An exemplary characteristic of the battery terminal voltage fitted by 6th order and 10th order polynomial equations (from test results of SAMSUNG INR18650-25R battery).

The characteristic of terminal voltage could be expressed by high order polynomial as a variable of $k$. Then, the EMF and internal resistance of the battery can be expressed by high order polynomial with the state of charge $k$ as a variable.

$$
\left\{\begin{array}{l}
E(k)=a_{1} k^{n}+a_{2} k^{n-1}+\ldots+a_{n} k+a_{n+1} \\
R(A h)=b_{1} k^{n}+b_{2} k^{n-1}+\ldots+b_{n} k+b_{n+1}
\end{array}\right.
$$


Taking the SAMSUNG INR18650-25R battery as an example, the characteristic of the battery EMF and the internal resistance is shown in Figure 7 according to above-mentioned method and laboratory test results. With received characteristics of the EMF and the internal resistance, the coefficients of $9^{\text {th }}$ order polynomial equations, which fitting the characteristics determined, are presented (see Table 2). The similar results for Panasonic NCR-18650B battery are received. For the reason of limited texture, the results are not presented, as well as, the characteristics of batteries for different temperature conditions. With a series of characteristics of the same battery in different temperature, an additional coefficient could be introduced to describe the temperature effects.
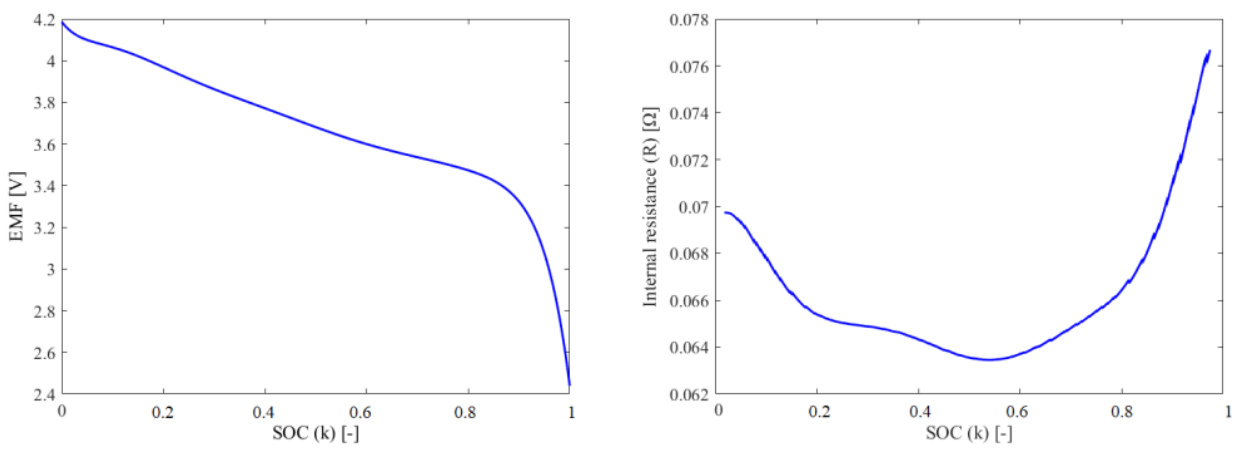

Fig. 7. Characteristics of battery EMF and internal resistance for SAMSUNG INR18650-25R received from test results and calculation at room temperature $\left(20^{\circ} \mathrm{C}\right)$.

Table 2. Coefficients of $9^{\text {th }}$ order polynomial equations for EMF and internal resistance of SAMSUNG INR18650-25R battery.

\begin{tabular}{|c|c|c|c|c|c|c|c|c|c|c|}
\hline \multirow{2}{*}{$E(k)$} & $a_{1}$ & $a_{2}$ & $a_{3}$ & $a_{4}$ & $a_{5}$ & $a_{6}$ & $a_{7}$ & $a_{8}$ & $a_{9}$ & $a_{10}$ \\
\cline { 2 - 11 } & -0.26664 & 2.8874 & -13.27 & 33.577 & -50.776 & 46.598 & -25.101 & 7.2216 & -1.2854 & 4.186 \\
\hline \multirow{2}{*}{$R(k)$} & $b_{1}$ & $b_{2}$ & $b_{3}$ & $b_{4}$ & $b_{5}$ & $b_{6}$ & $b_{7}$ & $b_{8}$ & $b_{9}$ & $b_{10}$ \\
\cline { 2 - 11 } & -0.021123 & 0.19452 & -0.71516 & 1.2978 & -1.0721 & 0.0061347 & 0.67432 & -0.47722 & 0.11685 & 0.060323 \\
\hline
\end{tabular}

\section{Conclusions}

This paper carries out an experimental approach to determine the proper parameters and coefficients of battery model which was developed by Antoni Szumanowski and Yuhua Chang. The laboratory tests are carried out on two types of Li-ion cylindrical cell batteries. Based on the laboratory test results, the proper method for determining the parameters and coefficients is described. According to the received parameters and coefficients, the characteristics of battery EMF and internal resistance are obtained for battery modelling. By increasing the order number of the polynomial equation for battery EMF and internal resistance, the error between the battery model and test results could be minimized.

In low-temperature conditions, the self-heating effect of the battery during its operation will increase the temperature of the battery body, which improves the battery EMF. The usable capacity of the battery drops significantly for the temperatures lower than $0^{\circ} \mathrm{C}$.

\section{References}

1. A. Szumanowski, Y.Chang, IEEE Transactions on Vehicular Technology, 57, (2008) 
2. M. Sekrecki, P. Krawczyk, A. Kopczyński, Logistyka: czasopismo dla profesjonalistów, 6, 9425, (2014)

3. Wen-Yeau Chang, A Review, Hindawi Publishing Corporation, ISRN Applied Mathematics, Article ID 953792, (2013)

4. ZHANG Di, MA Yan, BAI Qing-Wen, Proceedings of the 30th Chinese Control Conference, Yantai, China, (2011)

5. A. Kopczyński, Logistyka: czasopismo dla profesjonalistów, 3, 2269, (2015)

6. P. Krawczyk, A. Kopczyński, Proceedings of the Institute of Vehicles, 5, 31, (2016)

7. A. Kopczyński, P. Krawczyk, Proceedings of the Institute of Vehicles, 112 (3), 49, (2017).

8. Bingjun Xiao, Yiyu Shi, Lei He, Design Automation Conference (DAC), 47th ACM/IEEE, (2010).

9. Zhou Yongqin, Zhang Yanming, Zhao Pengshu, Han Chunli, The 6th International Forum on Strategic Technology, (2011).

10. Tesla vehicles batteries: https://www.tesla.com/fr_FR/blog/panasonic-presents-firstelectric-vehicle-battery-tesla

11. Nissan Leaf batteries: https://www.nissanusa.com/electric-cars/leaf/chargingrange/battery/

12. Samsung INR18650-25R datasheet available at: https://www.bto.pl/B2CProdukt.aspx?id_artykulu=49580

13. Panasonic NCR18650B datasheet available at: https://www.bto.pl/B2CProdukt.aspx?id_artykulu=42324 